\title{
К минералогии эксплозивных брекчий массива Салланлатва, Кольский регион
}

\author{
Сидоров М.Ю., Фомина Е.Н., Козлов Е.Н. \\ Геологический институт КНЦ РАН, Anamumbl, sidorov@geoksc.apatity.ru; fomina_e.n@mail.ru; \\ kozlov_e.n@mail.ru
}

Аннотация. Эксплозивные карбонатитовые брекчии массива Салланлатва характеризуются разнообразным минеральным составом обломков, вкрапленников и цемента, что свидетельствует об их позднем происхождении. Преимущественно карбонатный состав цемента брекчии указывает на повышенную активность карботермального флюида на поздних этапах образования массива. Поздние гидротермальные процессы проявились в образовании прожилков и каверн с Sr-Ti-REE минерализацией.

Ключевые слова: массив Салланлатва, карбонатиты, эксплозивные брекчии.

\section{On the mineralogical characteristics of explosive breccias of the Sallanlatva massif, Kola region}

\author{
Sidorov M.Yu., Fomina E.N., Kozlov E.N. \\ Geological Institute of KSCRAS, sidorov@geoksc.apatity.ru; fomina_e.n@mail.ru; kozlov_e.n@mail.ru
}

Abstract. The explosive carbonatite breccias of the Sallanlatva massif are characterized by varying mineralogical composition of rock fragments, phenocrysts, and matrix, which indicates the late formation of breccias. The predominance of carbonate composition of breccias matrix suggests a high activity of the carbothermal fluid at late formation stages of the massif. Late hydrothermal processes yielded veins and caverns with $\mathrm{Sr}$, Ti, and REE minerals.

Key words: Sallanlatva massif, carbonatites, explosive breccias.

\section{Введение}

Карбонатиты, входящие в состав многих щелочно-ультраосновных комплексов, являются уникальными геологическими объектами магматического происхождения. Карбонатитовые массивы характеризуются общей для большинства из них последовательностью образования от ранних кальциокарбонатитов через магнезиокарбонатиты к поздним феррокарбонатитам (Kapustin, 1980; Mitchell, 2005). Помимо карбонатов $\mathrm{Ca}, \mathrm{Mg}$ и $\mathrm{Fe}$ для карбонатитовых массивов характерна весьма разнообразная и подчас уникальная минерализация. Присутствие промышленных скоплений минералов Fe, P, а также высокозарядных (HFSE - Nb, Zr, Ti) и редкоземельных (REE) элементов делает карбонатитовые массивы важнейшим источником множества полезных ископаемых. Связанные с карбонатитовыми комплексами критически важные для современной промышленности месторождения HFSE и REE занимают лидирующие позиции как по запасам и ресурсам, так и по объемам добычи (Chakhmouradian, 2006; Mitchell, 2015; Richardson and Birkett, 1995; Simandl and Paradis, 2018). Значительная часть этих месторождений связана с поздними гидротермальными или карботермальными процессами, поэтому изучение поздних этапов образования и преобразования карбонитов является актуальным как в прикладном, так и в фундаментальном аспектах. Ценную информацию о протекании поздних процессов может дать исследование разнообразных брекчированных пород с карбонатитовым и силикокарбонатитовым цементом, часто формирующихся на завершающихся этапах становления карбонатитовых комплексов. Позднемагматические и постмагматические (в том числе эксплозивные процессы), приведшие к образованию карбонатитовых и силикокарбонатитовых брекчий, а также их положение в общей последовательности карбонатитогенеза ещё далеки от полного понимания и привлекают пристальный интерес (LeBas, 1977, 2008; Капустин, 1983; Kresten, 1988; Swinden and Hall, 2012)two main types of fenites occur: predominantly potassic fenites associated with ijolite intrusions, and predominantly sodic fenites associated with the intrusions of pyroxene sövites. The fenitization is described quantitatively by mass-transfer equations referring to the average wall-rock composition (AWR. 


\section{Геология массива Салланлатва}

Массив Салланлатва, расположенный в южной части Кольского региона, является одним из щелочно-ультраосновных комплексов девонской Кольской щелочной провинции (Zaitsev et al., 2014). Он является многофазной интрузией центрального типа, внешняя зона которой сложена мельтейгитами, внутренняя - ийолитами, а центральная -карбонатитами, которые являются наиболее молодыми образованиями массива (Серба, 1962; Кухаренко и др., 1965; Sitnikova et al., 2000). По своему составу Салланлатва отличается от других массивов Кольского региона наличием крупных тел, сложенных доломитовыми, анкеритовыми, брейнеритовыми, магнезитовыми и сидеритовыми карбонатитами (Zaitsev et al., 2004). Для карбонатитов Салланлатвы установлено присутствие промышленных концентраций Nb (луешит, пирохлор) и REE (анкилит, монацит) (Афанасьев, 2011). Другой особенностью массива являются значительные скопления барита в поздних доломитовых, магнезит-доломитовых, анкеритовых и сидеритовых карбонатитах (Афанасьев, 2011).

\section{Геология, петрография и минералогия карбонатитовых эксплозивных брекчий}

Эксплозивные карбонатитовые брекчии в массиве Салланлатва обнаружены только в пяти скважинах, пробуренных в 1980-х гг. во время геологоразведочных работ (Афанасьев, 2011).
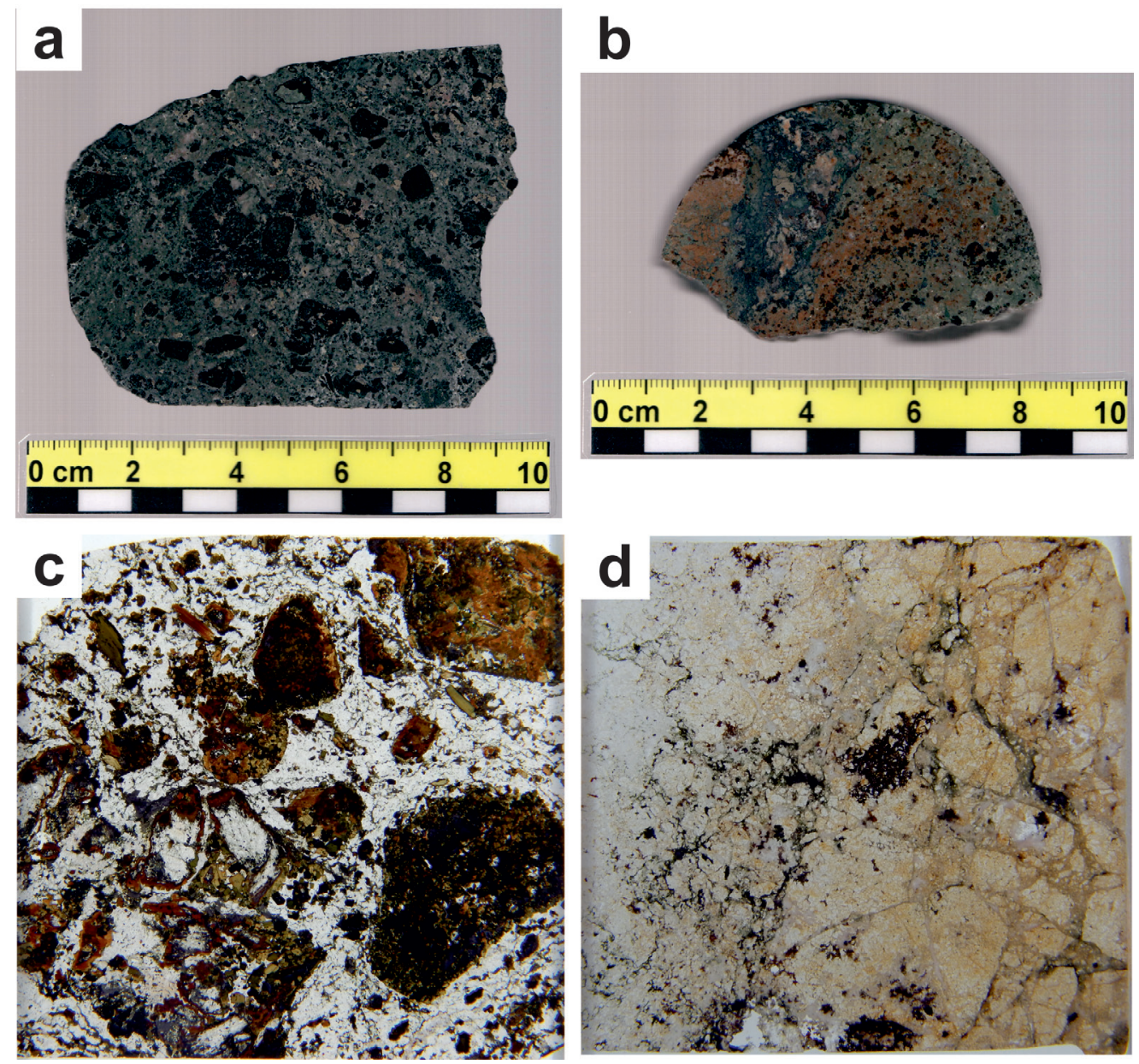

Рис. 1. а и $\mathrm{b}$ - полированные образцы эксплозивных брекчий массива Салланлатва; a - с глубины 229.5 м; $\mathrm{b}$ - с глубины 186.0 м. с - глиммеритовые обломки в сидерит-Fе-доломитовом цементе. $\mathrm{d}$ - сидеритовые обломки в хлорит-Fе-доломитовом цементе. Для рис. с и $\mathrm{d}$ ширина поля составляет 2.5 см. Fе-доломит - железистый доломит.

Fig. 1. $\mathrm{a}$ and $\mathrm{b}$ - polished samples of explosive breccias of the Sallanlatva massif; $\mathrm{a}$ - the sample from the depth of $229.5 \mathrm{~m} ; \mathrm{b}$ - sample from the depth of $186.0 \mathrm{~m}$. c - glimmerite fragments in the siderite-Fe-dolomite matrix. $\mathrm{d}$ - siderite fragments in the chlorite-Fe-dolomite matrix. The field width for Figures $\mathrm{c}$ and $\mathrm{d}$ is $2.5 \mathrm{~cm}$. Fe-dolomite - ferrous dolomite. 
На дневной поверхности они не найдены, и морфология их тел не установлена. В нашем исследовании мы приводим данные по эксплозивным карбонатитовым брекчиям, выявленных в керне одной из этих скважин. Наклонная скважина вскрыла два крутозалегающих тела эксплозивных брекчий. По направлению от центра массива к его краю первое тело вскрыто в интервале 175.0-191.8 м (истинная мощность 9.3 м), а второе - в интервале 228.0-258.0 м (истинная мощность 11.2 м). Выше- и нижележащими по положению в скважине породами для брекчий являются сидерит-анкеритовые карбонатиты, а в интервале между брекчиями залегают флогопит-кальцитовые карбонатиты с луешитом и обломками ийолитов.

Эксплозивные брекчии представляют собой гибридные породы с брекчиевой текстурой (рис. 1 a и b) и гипидиоморфнозернистой, флюидальной или порфировидной структурой цемента. Форма обломков угловатая, иногда угловато-округленная. В изученных нами образцах обломки представлены глиммеритами (рис. 1, с) и сидеритовыми карбонатитами (рис. 1, d). В эксплозивных брекчиях из других скважин среди обломков встречаются пироксениты, ийолиты, кальцитовые и анкеритовые карбонатиты, а также флогопит-франколитовые породы (Афанасьев, 2011). Также в цементе присутствуют вкрапленники магнетита, пирита и барита. Выделяются два типа цемента, главные минералы которых представлены железистым доломитом, сидеритом, баритом, хлоритом (шамозитом), стронцианитом, гематитом. Вариации содержания этих минералов на отдельных участках породы определяют тип цемента. Цемент первого типа представляет собой мелкосреднезернистую массу, сложенную преимущественно железистым доломитом, в котором присутствуют многочисленные вкрапленники $\mathrm{Mg}$-сидерита, а также ксеноморфные образования барита и стронцианита. Цемент второго типа - мелкозернистая порода, состоящая из агрегата железистого доломита и хлорита. В цементах обоих типов присутствуют многочисленные каверны. Часть каверн заполнена поздним стронцианитом, анкилитом-(Ce), рабдофаном-(Ce), а также оксидами Ті и гидроксидами Fe. Минеральный состав эксплозивных карбонатитовых брекчий характеризуется большим разнообразием (ниже по тексту приведены формулы лишь тех фаз, чьи кристаллохимические формулы не полностью отвечают «идеальным» формулам соответствующих минералов).

Сульфиды представлены в основном вкрапленниками кубических кристаллов пирита $\left[\mathrm{Fe}_{\text {0.9-1.0 }} \mathrm{Co}_{\text {0.0-0.1 }} \mathrm{S} \mathrm{S}_{2}\right.$, который иногда встречается в виде цементирующей массы для кристаллов железистого доломита и сидерита. В меньшей степени распространены пирротин $\left[\mathrm{Fe}_{0.8} \mathrm{~S}\right]$, галенит $\left[\mathrm{Pb}_{1.00} \mathrm{Fe}_{0.0-0.1} \mathrm{~S}\right]$, халькопирит, сфалерит $\left[\mathrm{Zn}_{0.8-0.9} \mathrm{Fe}_{0.1-0.2} \mathrm{~S}\right]$, гессит $\left[\mathrm{Ag}_{2} \mathrm{Te}\right]$ и $\mathrm{Pb}-\mathrm{Bi}-\mathrm{S}$ фаза, главным образом встречающиеся в виде мелких включений в кристаллах пирита.

Оксиды представлены вкрапленниками кристаллов магнетита $\left[\mathrm{Fe}^{2+}{ }_{1.01 .2} \mathrm{Fe}^{3+}{ }_{1.52 .00} \mathrm{Si}_{0.00 .2} \mathrm{Ti}_{0.0-0.1} \mathrm{O}_{4}\right]$, а также небольшими кристаллами пирохлора. В кристаллах пирохлора часто наблюдается зональность: сильно трещиноватая центральная зона $\left[\left(\mathrm{Ca}_{0.3} \mathrm{Ce}_{0.1} \mathrm{Ba}_{0.1} \mathrm{Na}_{0.1} \mathrm{U}_{0.1}\right)_{0.7}\left(\mathrm{Nb}_{1.5-1.65} \mathrm{Fe}^{3+}{ }_{0.2} \mathrm{Ti}_{0.1} \mathrm{Ta}_{0.1}\right)_{1.9-2.0} \mathrm{O}(\mathrm{OH})\right]$ и внешняя часть с хорошо проявленной осциляторной зональностью[ $\left[\left(\mathrm{Ca}_{0.9} \mathrm{Na}_{0.5-1.0} \mathrm{Ce}_{0.1}\right)_{1.5-2.0}\left(\mathrm{Nb}_{1.6-1.9} \mathrm{Si}_{0.0-0.2}\right.\right.$ $\left.\left.\mathrm{Ti}_{\text {0.0-0.2. }}\right)_{1.9-2.0} \mathrm{O}_{6}\left(\mathrm{~F}_{\text {0.8-1.0. }} \mathrm{OH}_{\text {0.0-0.2. }}\right)_{1.0}\right]$. Гематит образует очень мелкую рассеянную вкрапленность в небольших участках цемента из железистого доломита. Ильменит $\left[\mathrm{Fe}_{0.9-1.0} \mathrm{Ti}_{0.8-1.0} \mathrm{Nb}_{\text {0.0-0.2 }} \mathrm{O}_{3}\right]$ и оксиды титана, часто со значительным содержанием $\mathrm{Nb}$ выполняют поздние тонкие прожилки в брекчии.

Карбонаты слагают основной объём брекчий и представлены как в обломках, так и в цементе брекчии. Железистый доломит $\left[\mathrm{Ca}_{0.5} \mathrm{Mg}_{0.3-0.4} \mathrm{Fe}_{0.2} \mathrm{CO}_{3}\right]$ является основным минералом цемента брекчий. «Чистый»доломит $\left[\mathrm{Ca}_{0.5} \mathrm{Mg}_{0.5}\left(\mathrm{CO}_{3}\right)\right]$ образует редкие ксеноморфные зёрна в цементе из железистого доломита. Кальцит $\left[\mathrm{Ca}_{0.9-1.0} \mathrm{Mg}_{0.0-0.1} \mathrm{Fe}_{\text {0.0-0.1 }}\left(\mathrm{CO}_{3}\right)\right]$ также представлен отдельными кристаллами в цементе из железистого доломита. Сидерит $\left[\mathrm{Fe}_{\text {0.7-0.9 }} \mathrm{Mg}_{0.1-0.2} \mathrm{Mn}_{\text {0.0-0.1 }}\left(\mathrm{CO}_{3}\right)\right]$ встречается в виде обломков и вкрапленников в цементе, а также является составной частью цемента, образуя срастания с железистым доломитом. Витерит $\left[\mathrm{Ba}_{0.91 .0} \mathrm{Sr}_{0.0-0.1}\left(\mathrm{CO}_{3}\right)\right]$ встречен в виде отдельных зёрен в барите. Анкилит- $(\mathrm{Ce})\left[\left(\mathrm{Ce}_{0.5-0.6} \mathrm{La}_{0.3-0.4} \mathrm{Nd}_{0.1} \mathrm{Pr}_{0.1}\right)_{0.9-1.0} \mathrm{Sr}_{1.0-1.1}\left(\mathrm{CO}_{3}\right)_{2}(\mathrm{OH})\left(\mathrm{H}_{2} \mathrm{O}\right)\right]$ выполняет мелкие прожилки и каверны в цементе брекчий. Стронцианит обычно образует ксеноморфные зёрна в цементе в ассоциации с баритом, встречается в виде прожилков и, вместе с анкилитом-(Се) и поздним баритом, выполняет каверны. Бредлеит $\left[\left(\mathrm{Na}_{2.2-2.6}\right)\left(\mathrm{Mg}_{0.3-0.4} \mathrm{Fe}_{0.4} \mathrm{Mn}_{0.1}\right)_{0.9}\left(\mathrm{P}_{1.1} \mathrm{O}_{4}\right)\left(\mathrm{CO}_{3}\right)\right]$, безводный карбонат $\mathrm{Na}$ и $\mathrm{Mg}$ со значительной примесью Fе и с дополнительным анионом $\left(\mathrm{PO}_{4}\right)$, встречен в виде неболь- 
ших включений в пирите. Ранее бределеит был найден в массиве Салланлатва как дочерний минерал во флюидных включениях и в виде твердофазных включений в луешите и магнетите в кальцитовых карбонатитах (Zaitsev et al., 2004).

Из сульфатов в эксплозивной брекчии выявлен лишь барит. Он распространен как в обломках глиммеритов, где он цементирует кристаллы биотита, так и в цементе. В цементе барит встречается в виде крупных вкрапленников и прожилков, а иногда он цементирует раздробленные вкрапленники сидерита и пирита.

Фосфаты представлены апатитом $\left[\left(\mathrm{Ca}_{4.7-5.0} \mathrm{Na}_{0.3} \mathrm{Mn}_{0.0-0.1} \mathrm{Fe}_{0.1} \mathrm{Sr}_{0.1}\right)_{5.0-5.1}\left(\mathrm{PO}_{4}\right)_{2.9-3.0}\left(\mathrm{~F}_{0.00 .6} \mathrm{OH}_{0.4-1.0}\right)\right]$ и рабдофаном-(Се) и встречаются в виде небольших зёрен в цементе брекчии.

Силикаты представлены биотитом $\left[\left(\mathrm{K}_{0.9} \mathrm{Na}_{0.0-0.0 .1}\right)_{0.9-1.0}\left(\mathrm{Fe}^{2+}{ }_{0.8-1.8} \mathrm{Mg}_{1.2-2.1} \mathrm{Ti}_{0.2}\right)_{3.0-3.1}\left(\mathrm{Si}_{2.8-2.9} \mathrm{Al}_{1.1}\right)_{3.9} \mathrm{O}_{10}(\mathrm{OH})_{2}\right]$, который слагает глиммеритовые обломки и тонкозернистыми агрегатами минералов группы хлорита переменного состава, которые вместе с железистым доломитом образуют цемент второго типа.

\section{Выводы}

Разнообразие минерального состава эксплозивных карбонатитовых брекчий массива Салланлатва свидетельствует о вовлечении в процесс их образования ранее сформированных пород (глиммеритов, пироксенитов, ийолитов, кальцитовых, доломитовых и сидеритовых карбонатитов). Это также подтверждается присутствием в цементе брекчий таких «сквозных» для массива Салланлатва минералов, как магнетит, пирохлор и барит. Преимущественно железисто-доломитовый и сидеритжелезисто-доломитовый состав цемента брекчий указывает на то, что карботермальный флюид на завершающих этапах образования массива оставался ещё в достаточных количествах и находился в таких термодинамических условиях, которые привели к его взрывному внедрению в ранее образованные породы. Более поздним были гидротермальные процессы образования прожилков и каверн, выполненных $\mathrm{Nb}$-содержащими оксидами титана, рабдофаном-(Се), акилитом-(Cе) и стронцианитом в цементе брекчий.

\section{Благодарность}

Авторы выражают глубочайшую благодарность сотрудникам ТФГИ по СЗФО за оказанное содействие.

Работа выполнена в рамках исследовательского проекта Российского научного фонда «Механизм образования поздних редкометальных (РЗЭ, $\mathrm{Nb}$ ) карбонатитов: от магмогенерации до гипергенеза» № 19-77-10039. Отбор керна производился из коллекции ТФГИ по СЗФО в рамках темы НИР ГИ КНЦ РАН № 0226-2019-0053.

\section{Литература}

1. Афанасьев Б.В. Минеральные ресурсы щёлочно-ультраосновных массивов Кольского полуострова. СПб. Изд-во: «Роза ветров». 2011. 224 с.

2. Капустин Ю.Л. Трубки взрыва в карбонатитовых комплексах // Советская геология. 1983. Т. 4. С. $102-114$.

3. Кухаренко А.А., Орлова М.П., Булах А.Г., Багдасаров Э.А., Римская-Корсакова О.А., Нефёдов Е.И., Ильинский Г.А., Сергеев А.С., Абакумова Н.Б. Каледонский комплекс ультраосновных, щелочных пород и карбонатитов Кольского полуострова и северной Карелии. Москва. Изд-во: Недра. 1965. 772 с.

4. Серба Б.И. Салланлатвинский массив щелочных пород и карбонатитов // Магматические образования Кольского полуострова. Л. Изд-во: АН СССР. 1962. С. 58-64.

5. Chakhmouradian A. R. High-field-strength elements in carbonatitic rocks: Geochemistry, crystal chemistry and significance for constraining the sources of carbonatites // Chemical Geology. 2006. V. 235(1-2). P. 138-160. Doi:10.1016/j.chemgeo.2006.06.008.

6. Kapustin Y.L. Mineralogy of Carbonatites: Amerind Publishing, New Delhi. 1980. 259 p.

7. Kresten P. The chemistry of fenitization: Examples from Fen, Norway // Chemical Geology. 1988. V. 68(3-4). P. 329-349. Doi:10.1016/0009-2541(88)90030-7.

8. Le Bas M.J.: Carbonatite-Nephelinite Volcanism: an African Case History, Kluwer Academic Publishers., 1977. $347 \mathrm{p}$.

9. Le Bas M. J. Fenites associated with carbonatites // Canadian Mineralogist. 2008. V. 46(4). P. 915-932. Doi:10.3749/canmin.46.4.915, 2008. 
10. Mitchell R.H. Carbonatites and carbonatites and carbonatites // Canadian Mineralogist. 2005.V. 43. P. $2049-2068$. Doi: 10.2113/gscanmin.43.6.2049.

11. Mitchell, R. H. Primary and secondary niobium mineral deposits associated with carbonatites // Ore Geology Review. 2015. V. 64. P. 626-641. Doi:10.1016/j.oregeorev.2014.03.010, 2015.

12. Richardson D.G. and Birkett T.C. Carbonatite-Associated Deposits, in Geology of Canadian Mineral Deposit Types // Geological Society of America. 1995. P. 541-558.

13. Simandl G.J. and Paradis S. Carbonatites: related ore deposits, resources, footprint, and exploration methods // Applied Earth Science. 2018. V. 127(4). P. 123-152. Doi:10.1080/25726838.2018.1516935, 2018.

14. Sitnikova M.A., Zaitsev A.N., Wall F., Chakhmouradian A.R., Subbotin V.V. Evolution of chemical composition of rock-forming carbonates in Sallanlatvi Carbonatites, Kola Peninsula, Russia // Journal fo African Earth Sciences, 2001. V. 32. Issue 1. P. A-34.

15. Swinden S. and Hall, M. NI 43-101 Technical Report and Mineral Resource Estimate for the Songwe Hill Rare Earth Element (REE) Project, Phalombe District, Republic of Malawi. 2012.

16. Zaitsev A.N., Sitnikova M.A., Subbotin V.V., Fernández-Suárez, J. and Jeffries, T. E. Sallanlatvi Complex - a rare example of magnesite and siderite carbonatites, in Phoscorites and carbonatites from mantle to mine // Mineralogical Society of Great Britain and Ireland. 2004. P. 201-245.

17. Zaitsev A.N., Terry Williams, C., Jeffries, T.E., Strekopytov, S., Moutte, J., Ivashchenkova O.V., Spratt, J., Petrov S.V., Wall F., Seltmann R. and Borozdin A.P. Rare earth elements in phoscorites and carbonatites of the Devonian Kola Alkaline Province, Russia: Examples from Kovdor, Khibina, Vuoriyarvi and Turiy Mys complexes // Ore Geology Review. 2014.V. 61. P. 204-225. Doi:10.1016/j.oregeorev.2014.02.002, 2014. 